\title{
THE
}

1998

\section{Model results of flow instabilities in the tropical Pacific Ocean}

\author{
Kathleen A. Donohue \\ University of Rhode Island, kdonohue@uri.edu \\ Mark Wimbush \\ University of Rhode Island, mwimbush@uri.edu
}

Follow this and additional works at: https://digitalcommons.uri.edu/gsofacpubs

Terms of Use

All rights reserved under copyright.

\section{Citation/Publisher Attribution}

Donohue, K. A., and M. Wimbush (1998), Model results of flow instabilities in the tropical Pacific Ocean, J. Geophys. Res., 103(C10), 21401-21412, doi: 10.1029/98JC01912.

Available at: https://doi.org/10.1029/98JC01912

This Article is brought to you for free and open access by the Graduate School of Oceanography at DigitalCommons@URI. It has been accepted for inclusion in Graduate School of Oceanography Faculty Publications by an authorized administrator of DigitalCommons@URI. For more information, please contact digitalcommons-group@uri.edu. 


\title{
Model results of flow instabilities in the tropical Pacific Ocean
}

\author{
Kathleen A. Donohue ${ }^{1}$ and Mark Wimbush \\ Graduate School of Oceanography, University of Rhode Island, Narragansett
}

\begin{abstract}
A two-and-a-half-layer model of the tropical Pacific Ocean is used to investigate the energy source for the intraseasonal dynamic-height variability observed near $6^{\circ} \mathrm{N}$. A simulation of equatorial circulation is produced by forcing the model with mean-monthly wind-stress climatology. Two westward-propagating waves appear in the upper layer in the central and eastern portion of the model basin. These two waves are distinguished by period and meridional structure. An offequatorial wave with period of 30 days and wavelength of $1100 \mathrm{~km}$ has a meridional sea-level maximum near $6^{\circ} \mathrm{N}$ similar to that of the 30-50 day intraseasonal wave observed in the ocean. The meridional velocity signal also is asymmetric with respect to the equator, with 'maximum near $4^{\circ} \mathrm{N}$. The second wave with period of 15 days has a strong meridional velocity signal centered on the equator. The sealevel and zonal velocity signals associated with this equatorial wave have maxima near $1.5^{\circ} \mathrm{N}$ and $1.5^{\circ} \mathrm{S}$. The eddy-energy budget reveals strong conversions from the mean-flow to eddy field through baroclinic and upper-layer barotropic conversion terms. Conversion terms north of the equator exhibit a bimodal structure: one maximum between the equator and $3^{\circ} \mathrm{N}$ is dominated by upper-layer barotropic conversion spatially coincident with the cyclonic shear along the equatorward edge of the South Equatorial Current (SEC), and a second smaller maximum between $3^{\circ} \mathrm{N}$ and $5^{\circ} \mathrm{N}$ is a combination of upper-layer barotropic conversion along the poleward edge of the SEC (anticyclonic shear) and baroclinic conversion near the core of the SEC. The two peaks in the conversion terms, combined with similar structure in the flux-divergence terms in the model eddy-energy budget, provide evidence that two wave processes are generated at the different source regions: one near the equator and a second between $2^{\circ} \mathrm{N}$ and $5^{\circ} \mathrm{N}$.
\end{abstract}

\section{Introduction}

The parallel shear flows that characterize the equatorial circulation are potential sites for instabilities. Observations of the equatorial Pacific Ocean reveal annual bursts of synoptic-scale motions (zonal wavelengths of order $1000 \mathrm{~km}$ and periods of order 1 month) strong in boreal summer, fall, and winter, except during El Niño events when they are absent [e.g., Philander et al., 1985]. These motions, presumably the result of instabilities within the wind-driven near-surface currents, play an important role in the heat, momentum, and energy balances of the tropical Pacific. At first, researchers attempted to link all annually modulated synoptic motions to a single dynamical process; more recent

\footnotetext{
${ }^{1}$ Now at School of Ocean and Earth Science and Technology, University of Hawaii, Honolulu

Copyright 1998 by the American Geophysical Union.

Paper number 98JC01912.

0148-0227/98/98JC-01912\$09.00
}

analyses of observations and numerical models indicate that multiple instabilities may exist within the region [Luther and Johnson, 1990; McCreary and Yu, 1992]. Analysis of upper ocean current and density fields by Luther and Johnson [1990] suggests three different instabilities take place, each at a different phase of the seasonal cycle: one instability results from shear between Equatorial Undercurrent (EUC) and South Equatorial Current (SEC) during boreal summer and fall, and two result from conversion of mean-flow to eddypotential energy, one along the equatorial density front during boreal winter and one in the North Equatorial Countercurrent (NECC) thermocline during spring. In a two-and-a-half-layer model, McCreary and Yu [1992] produced multiple instabilities within the equatorial circulation: a surface-trapped wave associated with the temperature front, a lower-layer wave associated with equatorial undercurrent meanders, and a third mode resembling a first-meridional-mode Rossby wave. Different energy sources for the various possible instabilities presumably occur at different times and at different latitudes. 
Qiao and Weisberg [1995] provided a review of tropical instability wave observations and a detailed kinematic study of equatorial tropical instability waves observed during the Tropical Instability Wave Experiment (TIWE). They found the waves are confined to narrow period and zonal wavelength ranges centered at 21 days and $1060 \mathrm{~km}$, respectively, and westward phase speed of $59 \mathrm{~cm} \mathrm{~s}^{-1}$. Tropical instability waves at and just north of the equator are linked to a barotropic instability mechanism between the SEC and the upper core of the EUC [Qiao and Weisberg, 1998]; the initial onset of the instability is dominated by significant conversions from mean-flow kinetic energy to eddy-kinetic energy, a signature of barotropic instability. There is also evidence for conversion of mean-flow potential energy to eddy-kinetic energy during the wave season, indicating that baroclinic instability may be an important secondary process. These recent results are consistent with previous observations [Hansen and Paul, 1984] and numerical modeling efforts [Semtner and Holland, 1980; Cox, 1980].

However, synoptic variability is not confined to the near-equatorial region. According to Périgaud [1990] and Giese et al. [1994], altimeter data reveal anticyclonic eddies propagating westward in the region $5^{\circ}$ $7^{\circ} \mathrm{N}, 110^{\circ}-165^{\circ} \mathrm{W}$ Both studies are in good agreement, reporting periods of $28-40$ days and phase speeds of 35$45 \mathrm{~cm} \mathrm{~s}^{-1}$, slightly longer in period and slower in speed than the equatorial observations of Qiao and Weisberg [1995]. Flament et al. [1996] reported that measurements taken during TIWE reveal an anticyclonic vortex centered at $4^{\circ} \mathrm{N}$. Although the direct connection has yet to be established, this vortex is presumably related to the sea-level anomalies viewed by the altimeter. The presence of this vortex indicates synoptic-scale variability near $5^{\circ} \mathrm{N}$ may be distinct from that closer to the equator, but McPhaden [1996] argued that meridional advection creates the "red shift" seen in the offequatorial temperature spectrum.

While synoptic-scale waves generally have $\sim 1000 \mathrm{~km}$ wavelength and share a common annual and interannual modulation, little attention has been given to the meridional structure of these waves. The relationship between the strong velocity signal close to the equator and the strong pressure signal off the equator remains undetermined. The seasonally modulated synoptic signal in the upper-equatorial Pacific Ocean may be more complex than a single instability wave; perhaps more than one seat of instability exists, as suggested by Luther and Johnson [1990] and McCreary and Yu [1992].

This paper investigates the relationship between instabilities in the equatorial current system and the offequatorial variability in the Pacific Ocean east of the date line. In a study by Donohue et al. [1994], spatial and temporal features of central equatorial Pacific Ocean sea-level variation appear similar in measurements from two different systems (in situ and satellite) and in the results from a numerical model of the re- gion, the global version of the Navy layered ocean model [Wallcraft, 1991]. In particular, synoptic-scale oscillations appear at $6^{\circ} \mathrm{N}$, and are strongest around the end of each non-El Niño calendar year. Since location, timing, wavelength, and period of the instability in the numerical model and in the observations are in good agreement, this model is used in the current study to analyze this instability and hence help us understand its dynamics.

\section{Model}

The folowing equations are solved by the isopycnal two-and-a-half-layer ocean model used in this study [Wallcraft, 1991]. The subscript $i$ indicates the layer. Unless otherwise stated, $i=1,2$.

$$
\begin{aligned}
\frac{\partial h_{i} \mathbf{v}_{i}}{\partial t}+ & \left(\nabla \cdot h_{i} \mathbf{v}_{i}+h_{i} \mathbf{v}_{i} \cdot \nabla\right) \mathbf{v}_{i}+\hat{k} \times f h_{i} \mathbf{v}_{i} \\
= & -h_{i} \frac{\nabla p_{i}}{\rho_{o}}+\frac{\boldsymbol{\tau}}{\rho_{i}}+A_{H} \nabla^{2} h_{i} \mathbf{v}_{i} \\
& +\max \left[0,-\omega_{i-1}\right] \mathbf{v}_{i-1}+\max \left[0, \omega_{i}\right] \mathbf{v}_{i+1} \\
& -\left(\max \left[0,-\omega_{i}\right]+\max \left[0, \omega_{i-1}\right]\right) \mathbf{v}_{i} \\
\frac{\partial h_{i}}{\partial t}+ & \nabla \cdot h_{i} \mathbf{v}_{i}=\omega_{i}-\omega_{i-1} \\
\nabla p_{1}= & g\left(\rho_{1}-\rho_{3}\right) \nabla h_{1} \\
+ & g\left(\rho_{2}-\rho_{3}\right) \nabla h_{2} \\
\nabla p_{2}= & g\left(\rho_{2}-\rho_{3}\right) \nabla\left(h_{1}+h_{2}\right) \\
\nabla p_{3}= & 0 .
\end{aligned}
$$

Note that a repeated index does not imply summing here. The symbols are defined as follows:

$$
\begin{array}{rl}
h_{i}(x, y, t) & i \text { th layer thickness; } \\
\mathbf{v}_{i}(x, y, t)=\left(u_{i}, v_{i}\right) & \text { ith layer horizontal } \\
& \text { velocity; } \\
p_{i}(x, y, t) & \text { ith layer pressure; } \\
\tau(x, y, t) & \text { wind-stress vector; } \\
\rho_{o} & \text { reference density; } \\
\rho_{i} & i \text { th layer density; } \\
A_{H} & \text { coefficient of horizontal } \\
& \text { eddy viscosity; } \\
\nabla & \text { horizontal gradient operator; } \\
g & \text { acceleration due to gravity; } \\
\hat{k} & \text { unit vector directed } \\
& \text { vertically upward; } \\
f(y) & \text { Coriolis parameter; } \\
\omega_{i}(x, y, t) & i \text { th interface } \\
& \text { entrainment/detrainment } \\
& \text { (described below). }
\end{array}
$$

The lowest layer in a reduced-gravity model (here $i=3$ ) remains at rest during integration; therefore the hori- 
Table 1. Model Parameters Implemented in the Model Simulation

\begin{tabular}{ll}
\hline Parameter & Value \\
\hline Layers & $i=1$ (active), $i=2$ (active), $i=3$ (inactive) \\
Interfacial friction coefficient & 0 \\
Layer density $\rho_{i}$ & $1023.16,1025.34,1026.50 \mathrm{~kg} \mathrm{~m}^{-3}$ \\
Resting layer thickness $H_{2}$ & $110,130 \mathrm{~m}$ \\
Mixing velocity $\tilde{\omega}_{3}$ & $0.009,0.009 \mathrm{~m} \mathrm{~s}^{-1}$ \\
Mixing depth $h_{2}^{+}$ & $55,75 \mathrm{~m}$ \\
Time step $\Delta t$ & $43 \mathrm{~min}$ \\
Western boundary & $109.125^{\circ} \mathrm{E}$ \\
X longitudinal grid spacing & $0.703125^{\circ}$ \\
X longitudinal grid points & 248 \\
Southern boundary & $20^{\circ} \mathrm{S}$ \\
Y latitudinal grid spacing & $0.5^{\circ}$ \\
Y latitudinal grid points & 81 \\
Boundary conditions & no slip \\
Coastline & quasi-realistic coastline \\
Forcing & Hellerman-Rosenstein climatology \\
Horizontal eddy viscosity $A$ & $1500 \mathrm{~m}^{2} \mathrm{~s}^{-1}$ \\
\hline
\end{tabular}

Parameters listed with more than one value indicate values corresponding to the individual layers where $i=1,2,3$ from left to right.

zontal pressure gradient vanishes in this layer (see equation (5)).

Diapycnal mixing is parameterized by the model entrainment/detrainment. Mathematically, we express the entrainment/detrainment terms as

$$
\begin{aligned}
\omega_{i} & =\omega_{i}^{+}-h_{i} \hat{\omega}_{i}, \\
\omega_{i}^{+} & =\tilde{\omega}_{i}\left(\frac{\max \left(0, h_{i}^{+}-h_{i}\right)}{h_{i}^{+}}\right)^{2}, \\
\hat{\omega}_{i} & =\frac{\omega_{i}^{+} \iint d x d y}{\iint h_{i} d x d y}
\end{aligned}
$$

where we use the following: $\omega_{i}^{+}(x, y)$ is the $i$-th layer entrainment; $\tilde{\omega}_{i}$ is the $i$-th interface reference vertical mixing velocity; and $h_{i}^{+}$is the $i$-th layer thickness at which entrainment starts. Positive layer thicknesses are assured by the mixing of mass and momentum into an outcropping layer $\left(h_{i}<h_{i}^{+}\right)$from the layer below. Layer entrainment is balanced by global detrainment. A detailed discussion of this type of diapycnal mixing is found in the work by Shriver and Hurlburt [1997].

Model parameters implemented in this experiment are listed in Table 1. Mean layer thicknesses of 110 and $130 \mathrm{~m}$ are chosen as representative for the region, and the densities of these layers are based on suitable averages of Levitus [1982] oceanic climatology. The value of each $h_{i}^{+}$is chosen so that the EUC has realistic behavior [Hurlburt et al., 1992]. The model is integrated forward in time from an initial state of no motion, using mean-monthly wind-stress values from Hellerman and Rosenstein [1983]. The coastline is the $500 \mathrm{~m}$ isobath from the ETOP05 database of world bathymetry. After 10 years the fluctuations in total layer potential and kinetic energies are consistent from year to year, indicating the initial transients have died away. The model output is subsampled at intervals of 3 days over the entire model grid. The following discussion is based on analysis of 4 years of model integration (years 11-14). Analysis of model output highlights possible generation mechanisms for instability waves.

Aside from basic limitations inherent in any primitive equation numerical model (i.e., grid resolution, parameterization of mixing, etc.), the three most severe limitations in this study are low vertical resolution, absence of explicit thermodynamic processes, and artificial poleward boundaries. Slab-like flow within layers poorly resolves the vertical shears that exist in the ocean, for example, above and below the core of the EUC. Artificial poleward boundaries in this model sever communication with midlatitudes and allow artificial Kelvin-wave propagation along the boundaries. We accept these shortcomings because the fundamental goal of this modeling study is to reproduce and examine the instability-wave processes in the simplest framework possible.

\section{Model Results}

\subsection{Mean Conditions}

The structure of the mean currents provides a useful foundation for further analysis of the model output. Focusing on the central and eastern equatorial regions of the model, alternating bands of westward and eastward 

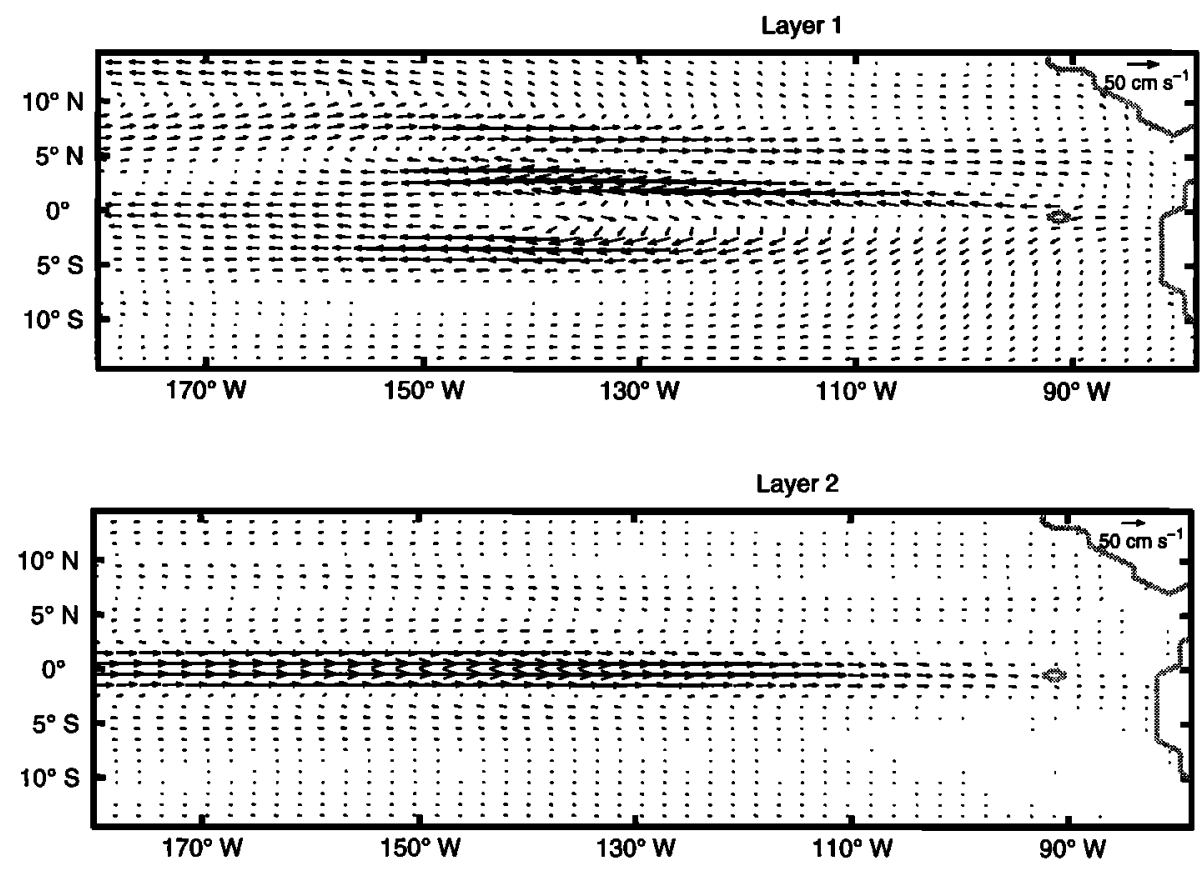

Figure 1. Mean velocity averaged over years 11-14 for model simulation: (top), upper-layer velocity; (bottom), lower-layer velocity.

flow appear in the 4-year upper-layer mean (Figure 1). In the upper layer the SEC flows westward in the direction of the prevailing winds. East of $150^{\circ} \mathrm{W}$ the SEC has two cores, one on either side of the equator. For longitudes $140^{\circ}-110^{\circ} \mathrm{W}$, weak eastward surface flow appears on the equator between these two cores. North of the SEC the eastward flow of the NECC reaches values of $40 \mathrm{~cm} \mathrm{~s}^{-1}$. The latitude band of the NECC depends on longitude: at $120^{\circ} \mathrm{W}$ it extends from $4^{\circ} \mathrm{N}$ to $8^{\circ} \mathrm{N}$ while at $160^{\circ} \mathrm{W}$ it is $2^{\circ}$ further north, extending from $6^{\circ} \mathrm{N}$ to $10^{\circ} \mathrm{N}$. Further west the current occupies a broad region between $2^{\circ} \mathrm{N}$ and $10^{\circ} \mathrm{N}$. A weak North Equatorial Current (NEC) exists with westward flows, strongest in the western portion of the basin. The EUC dominates the structure of the lower-layer velocity, flowing eastward with maximum speeds of $100 \mathrm{~cm} \mathrm{~s}^{-1}$ near $140^{\circ} \mathrm{W}$.

The seasonal variations in major currents at $155^{\circ} \mathrm{W}$, $140^{\circ} \mathrm{W}$, and $125^{\circ} \mathrm{W}$ are shown in Figure 2 . Model velocities have been low-pass filtered with a 90-day Butterworth filter (run forward and backward to avoid phase shifts). In general, the SEC and NECC exhibit boreal spring minima and boreal fall/winter maxima. The SEC appears as a split jet, a core north and south of the equator, throughout the year at $125^{\circ} \mathrm{W}$ and $140^{\circ} \mathrm{W}$, but only during February through May at $155^{\circ} \mathrm{W}$. The maximum in the strength of the SEC north of the equator (SECN) propagates westward during the year: $>80 \mathrm{~cm} \mathrm{~s}^{-1}$ from mid-June through mid-December at $125^{\circ} \mathrm{W},>80 \mathrm{~cm} \mathrm{~s}^{-1}$ from August through January at $140^{\circ} \mathrm{W}$, and $>60 \mathrm{~cm} \mathrm{~s}^{-1}$ from mid-February through mid-March at $155^{\circ} \mathrm{W}$. The NECC maximum at each longitude occurs before the SECN maximum and also propagates westward: $>40 \mathrm{~cm} \mathrm{~s}^{-1}$ from midMay through August at $125^{\circ} \mathrm{W},>60 \mathrm{~cm} \mathrm{~s}^{-1}$ in August at $140^{\circ} \mathrm{W}$, and $>40 \mathrm{~cm} \mathrm{~s}^{-1}$ from September through January at $155^{\circ} \mathrm{W}$. The poleward edge of the SECN progresses poleward from $4^{\circ} \mathrm{N}$ at $125^{\circ} \mathrm{W}$ to $5^{\circ} \mathrm{N}$ at $140^{\circ} \mathrm{W}$ to $4.5^{\circ}-6^{\circ} \mathrm{N}$ at $155^{\circ} \mathrm{W}$. At $155^{\circ} \mathrm{W}$ the poleward edge of the SECN has a strong seasonal cycle; the zero velocity contour is near $4.5^{\circ} \mathrm{N}$ during the boreal fall, but moves to about $6^{\circ} \mathrm{N}$ during February through May. After the boreal spring collapse of the SEC, the zero velocity contour migrates northward to $4.5^{\circ} \mathrm{N}$ during the summer. The EUC maximum propagates eastward : > $100 \mathrm{~cm} \mathrm{~s}^{-1}$ in mid-March through mid-April at $155^{\circ} \mathrm{W},>120 \mathrm{~cm} \mathrm{~s}^{-1}$ during mid-May through midJune at $140^{\circ} \mathrm{W}$, and $>80 \mathrm{~cm} \mathrm{~s}^{-1}$ during late June at $125^{\circ} \mathrm{W}$.

\subsection{Variability}

Eddy-kinetic energy is a measure of the energy of the fluctuating flow (indicated by primes) in the system. Total, mean-flow, and eddy kinetic energies are defined by

$$
\begin{aligned}
& \frac{1}{2} \rho \overline{h\left(u^{2}+v^{2}\right)}=\frac{1}{2} \rho \bar{h}\left(\bar{u}^{2}+\bar{v}^{2}\right) \\
& \quad+\frac{1}{2} \rho\left(\overline{h^{\prime}\left(u^{\prime 2}+v^{\prime 2}\right)}+\bar{h} \overline{u^{\prime 2}}+\bar{h} \overline{v^{\prime 2}}+\bar{u} \overline{h^{\prime} u^{\prime}}+\bar{v} \overline{h^{\prime} v^{\prime}}\right)
\end{aligned}
$$

where the left-hand side is total energy, the first term on the right-hand side is mean-flow kinetic energy, and the second term on the right-hand side is eddy kinetic energy. The overbar represents an average over the 4 

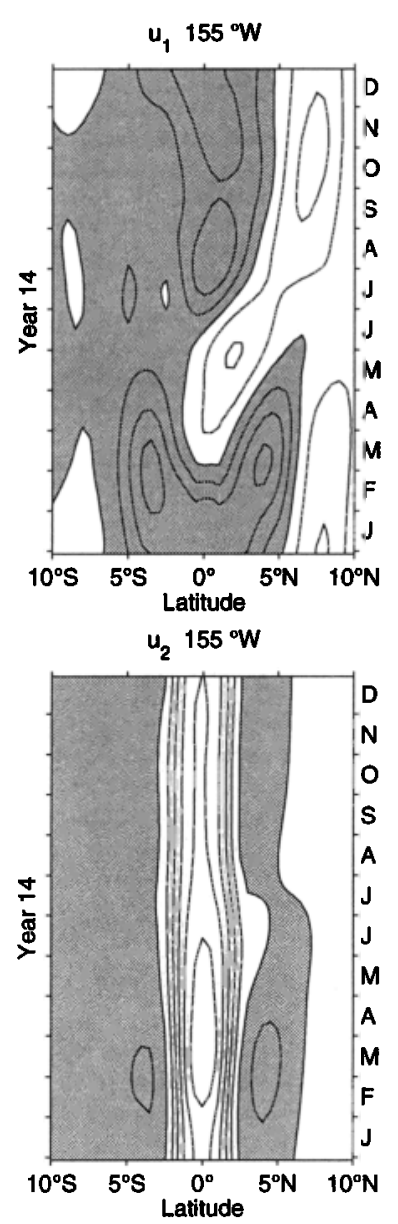

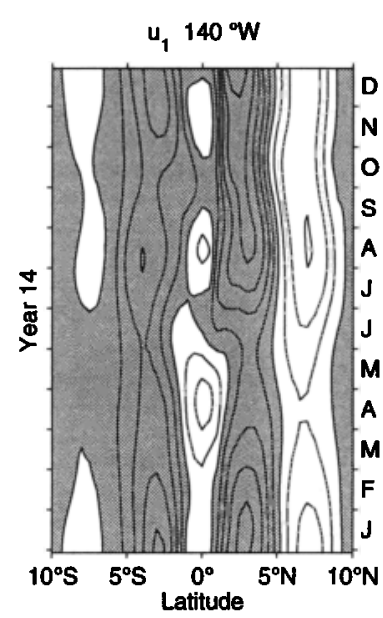

$u_{2} 140^{\circ} \mathrm{W}$

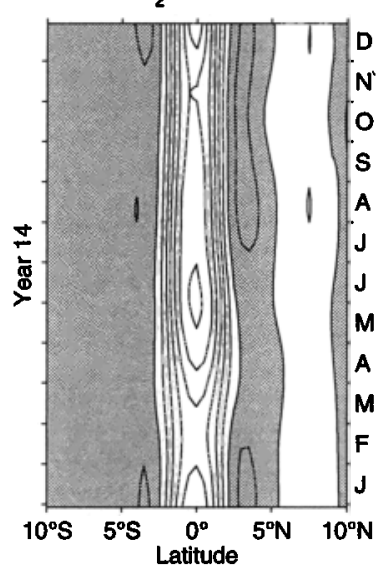

$u_{1} 125^{\circ} \mathrm{W}$

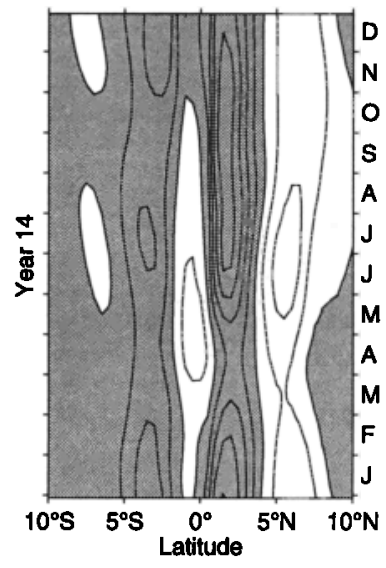

$u_{2} 125^{\circ} W$

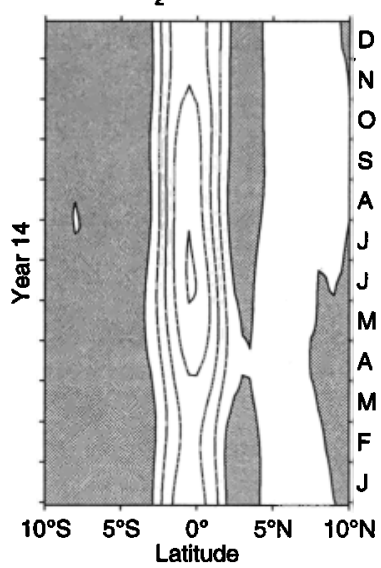

Figure 2. Upper-layer (top panels) and lower-layer (bottom panels) zonal velocity, at $155^{\circ} \mathrm{W}$ (left panels), $140^{\circ} \mathrm{W}$ (middle panels), and $125^{\circ} \mathrm{W}$ (right panels) contoured as a function of latitude and time. Zonal velocities have been low-pass filtered with a 90-day filter. Contour interval is $20 \mathrm{~cm} \mathrm{~s}^{-1}$. Shaded areas represent westward flow.

years. In the upper layer the mean-flow kinetic energy is concentrated in the central and east equatorial region; it is associated with the SEC and to a lesser extent the NECC. In the lower layer the mean-flow kinetic energy is concentrated in the vicinity of the EUC [Donohue, 1995]. Upper-layer eddy-kinetic energy (Figure 3) is highest near the equator west of $130^{\circ} \mathrm{W}$. Lower-layer eddy-kinetic energy (not shown) is a factor of 4 lower than the upper-layer eddy-kinetic energy in the central equatorial basin.
Strong variability in the region of high eddy-kinetic energy may represent the sum of several wave processes. How many wave processes are present? This issue is first addressed by evaluating the spectra of zonal and meridional velocity as well as sea level. High energy is seen to occur in periods between 15 and 50 days; two periods stand out, one near 15 days and the other near 30 days (Figure 4 ).

3.2.1. Fifteen-day waves. This spectral peak occurs in the upper-layer meridional velocity at the equa-

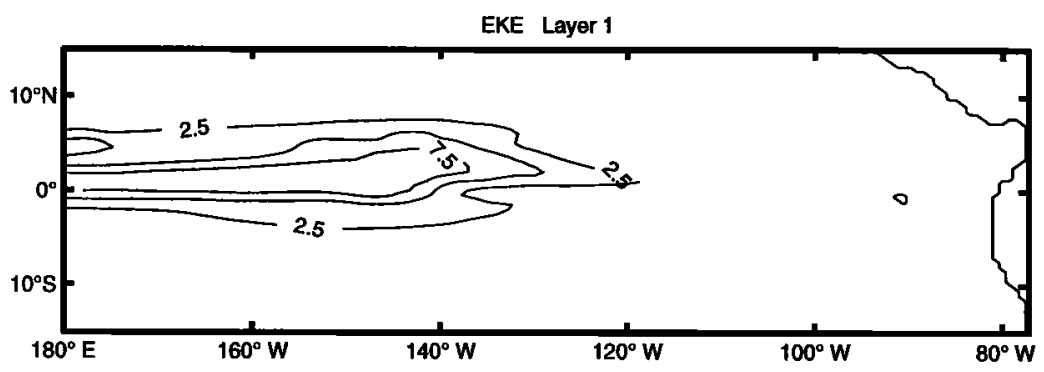

Figure 3. Upper-layer eddy-kinetic energy computed for the model years 11-14. Contour interval is $2.5 \times 10^{6} \mathrm{erg} \mathrm{cm}^{-2}$. 

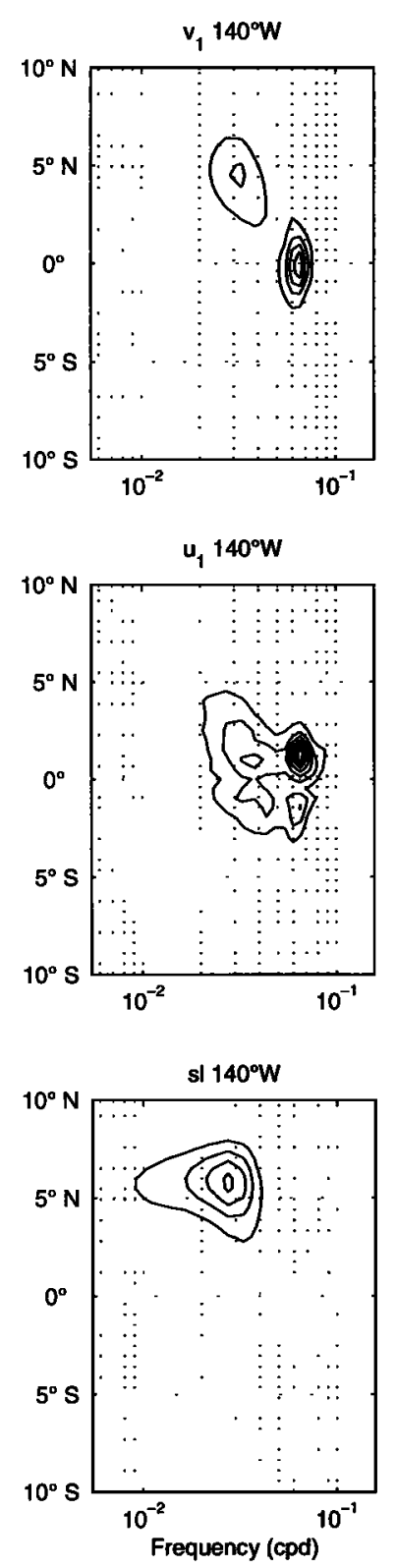

Figure 4. Spectra of (top) upper-layer meridional velocity, (middle) zonal velocity and (bottom) sea level along $140^{\circ} \mathrm{W}$, contoured in energy-preserving form $E f$ versus $\log f$. Contour interval for the meridional and zonal velocity fields is $400\left(\mathrm{~cm} \mathrm{~s}^{-1}\right)^{2}$ and $200\left(\mathrm{~cm} \mathrm{~s}^{-1}\right)^{2}$, respectively, while for sea level the contour interval is $10 \mathrm{~cm}^{2}$. Power spectrum, $E$, is computed so that $\int E \cdot \mathrm{d} f=$ variance of the time series. Principal peaks are at periods of 15 and 30 days.

tor, while for zonal velocity there are two off-equatorial energy peaks, at $1.5^{\circ} \mathrm{N}$ and $1.5^{\circ} \mathrm{S}$. A similar spectral plot (not shown) of equatorial meridional velocity computed as a function of longitude and frequency has maximum energy at $140^{\circ} \mathrm{W}$ and 15 days. The timelongitude contour plot (Figure 5) of the upper-layer meridional velocity on the equator illustrates the seasonal nature of the waves: maximum in boreal fall through winter and minimum in boreal spring. Phase

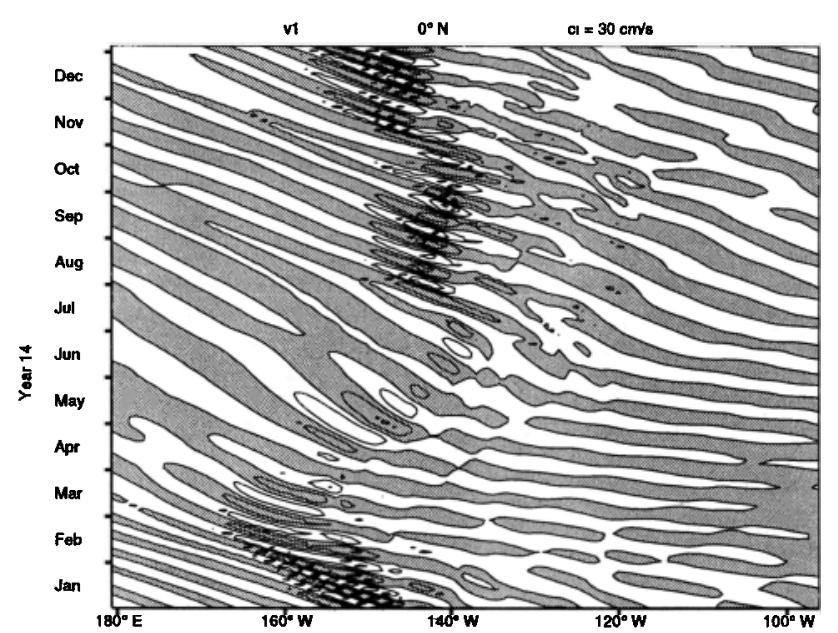

Figure 5. Upper-layer meridional velocity anomaly from year 14 of the model simulation on the equator, contoured as a function of time and longitude. Contour interval is $30 \mathrm{~cm} \mathrm{~s}^{-1}$. Shaded regions represent southward flow. A 4-year mean has been subtracted from each record. Estimated westward phase speed between $160^{\circ} \mathrm{W}$ and $132^{\circ} \mathrm{W}$ is $76 \mathrm{~km} \mathrm{~d}^{-1}$.

speed may be estimated from the data in such a diagram by the autocorrelation matrix method [Polito and Cornillon, 1997] which is used for all phase speeds computed in this paper. From the data of Figure 5, the phase velocity between $160^{\circ} \mathrm{W}$ and $132^{\circ} \mathrm{W}$ is $76 \mathrm{~km} \mathrm{~d}^{-1}$ westward $\left(1 \mathrm{~km} \mathrm{~d}^{-1}=1.16 \mathrm{~cm} \mathrm{~s}^{-1}\right)$.

3.2.2. Thirty-day waves. The sea-level spectrum plot (Figure 4, bottom panel) shows very little power near 15 days; most of the spectral energy is confined to periods near 30 days. This energy is located

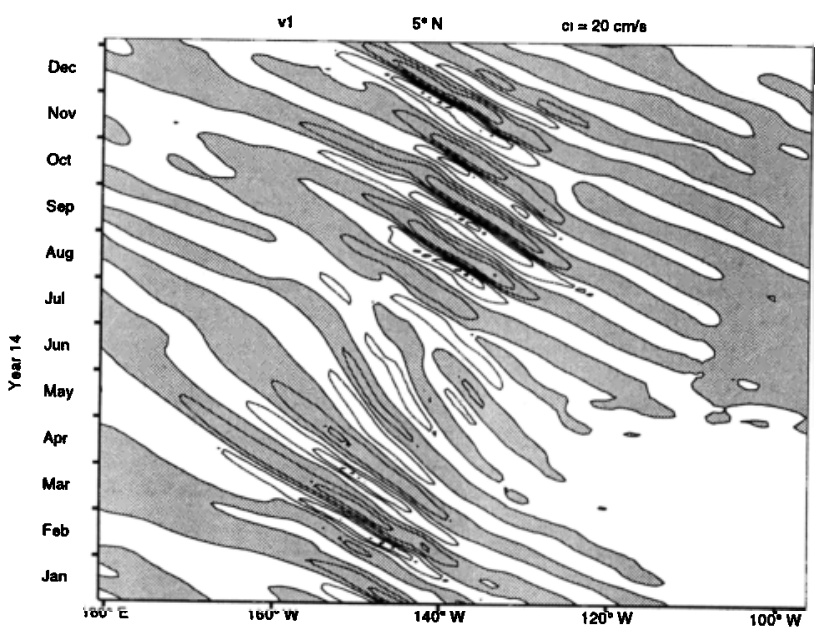

Figure 6. Upper-layer meridional velocity anomaly from year 14 of the model simulation at $5^{\circ} \mathrm{N}$ contoured as a function of time and longitude. Contour interval is $20 \mathrm{~cm} \mathrm{~s}^{-1}$. Shaded regions represent southward flow. A 4-year mean has been subtracted from each record. Estimated westward phase speed between $160^{\circ} \mathrm{W}$ and $132^{\circ} \mathrm{W}$ is $36 \mathrm{~km} \mathrm{~d}^{-1}$. 
near $6^{\circ} \mathrm{N}$, although there is a slight peak near $5^{\circ} \mathrm{S}$ at periods closer to 25 days. The corresponding spectral peak in meridional velocity is near $5^{\circ} \mathrm{N}$. The waves appear as regions of anticyclonic circulation around the high-pressure zones at $6^{\circ} \mathrm{N}$, with elevations of $10-15 \mathrm{~cm}$. A time-longitude contour plot (Figure 6) of meridional velocity from $5^{\circ} \mathrm{N}$ illustrates the seasonal modulation of the waves: maximum in boreal fall and minimum in boreal spring. Between $160^{\circ} \mathrm{W}$ and $132^{\circ} \mathrm{W}$ these waves propagate westward with a phase speed of $36 \mathrm{~km} \mathrm{~d}^{-1}$.

\subsection{Energetics}

An energetics analysis evaluates the nature of the energy exchange between mean and eddy fields. The appendix provides the details of the mean-flow and eddyenergy budgets for the model. The eddy-energy budget

$$
\frac{\partial \widehat{\mathcal{E}}}{\partial t}+\nabla \cdot \mathcal{F} \widehat{\mathcal{L U}} \mathcal{X}=\widehat{\mathcal{T}}+\widehat{\mathcal{D}}+\widehat{\mathcal{W}}+C
$$

indicates how energy is put into the eddy field, redistributed between mean and eddy fields, and finally taken out of the eddy-energy via small-scale dissipation $(\widehat{\mathcal{D}}) . \widehat{\mathcal{E}}$ is the total energy of the eddy field. The second term in (8) is a flux-divergence term representing spatial redistribution of eddy energy. Energy can be put into the eddy system through mechanical energy $(\widehat{\mathcal{T}})$, entrainment or detrainment processes $(\widehat{\mathcal{W}})$, or conversion between mean-flow and eddy field $(C)$.

The eddy-energy budget contains three types of conversion terms $(C)$ between mean-flow and eddy fields: Kelvin-Helmholtz, barotropic and baroclinic. Both the
Kelvin-Helmholtz conversion terms

$$
-\rho_{i} \overline{u_{i}} \overline{u_{i}^{\prime} \nabla \cdot \overline{h_{i}} \mathbf{v}_{i}^{\prime}}-\rho_{i} \overline{v_{i}} \overline{v_{i}^{\prime} \nabla \cdot \overline{h_{i}} \mathbf{v}_{i}^{\prime}}
$$

and the barotropic conversion terms

$$
\begin{aligned}
& -\rho_{\imath} \overline{h_{i}^{\prime} \mathbf{v}_{\imath}^{\prime}} \overline{u_{i}} \cdot \nabla \overline{u_{\imath}}-\rho_{i} \overline{h_{2}^{\prime} \mathbf{v}_{i}^{\prime}} \overline{v_{\imath}} \cdot \nabla \overline{v_{i}} \\
& -\rho_{\imath} \overline{h_{i}} \overline{\mathbf{v}_{i}^{\prime} u_{i}^{\prime}} \cdot \nabla \overline{u_{i}}-\rho_{i} \overline{h_{i}} \overline{\mathbf{v}_{\imath}^{\prime} v_{i}^{\prime}} \cdot \nabla \overline{v_{i}}
\end{aligned}
$$

represent the conversion from mean-flow kinetic to eddykinetic energy. McCreary and $Y u$ [1992] favored this separation of the mean-flow-kinetic to eddy-kinetic energy conversion into Kelvin-Helmholtz (9) and barotropic (10) conversion terms. The motivation for this division relies on the physical interpretation associated with each conversion. All the terms in the KelvinHelmholtz conversion contain $\nabla \cdot \overline{h_{i}} \mathbf{v}_{i}^{\prime}$, which is related to vertical velocity in the layered system [McCreary and $Y u, 1992]$. The terms in the barotropic conversion contain the gradient of the mean velocity, $\nabla \overline{u_{i}}$ or $\nabla \overline{v_{i}}$. Perturbations smooth the meridional gradients of the mean flow in barotropic instability. The baroclinic conversion is the conversion of mean-flow-potential to eddypotential energy and is represented by the steepening or leveling of mean interfacial slopes. Since potential energy is associated with interface displacement which affects $h_{\imath}$ in the layers above and below the interface, we consider the total baroclinic conversion:

$$
\sum_{i=1}^{2}-\overline{h_{i}^{\prime} \mathbf{v}_{i}^{\prime}} \cdot \nabla \overline{p_{i}} .
$$
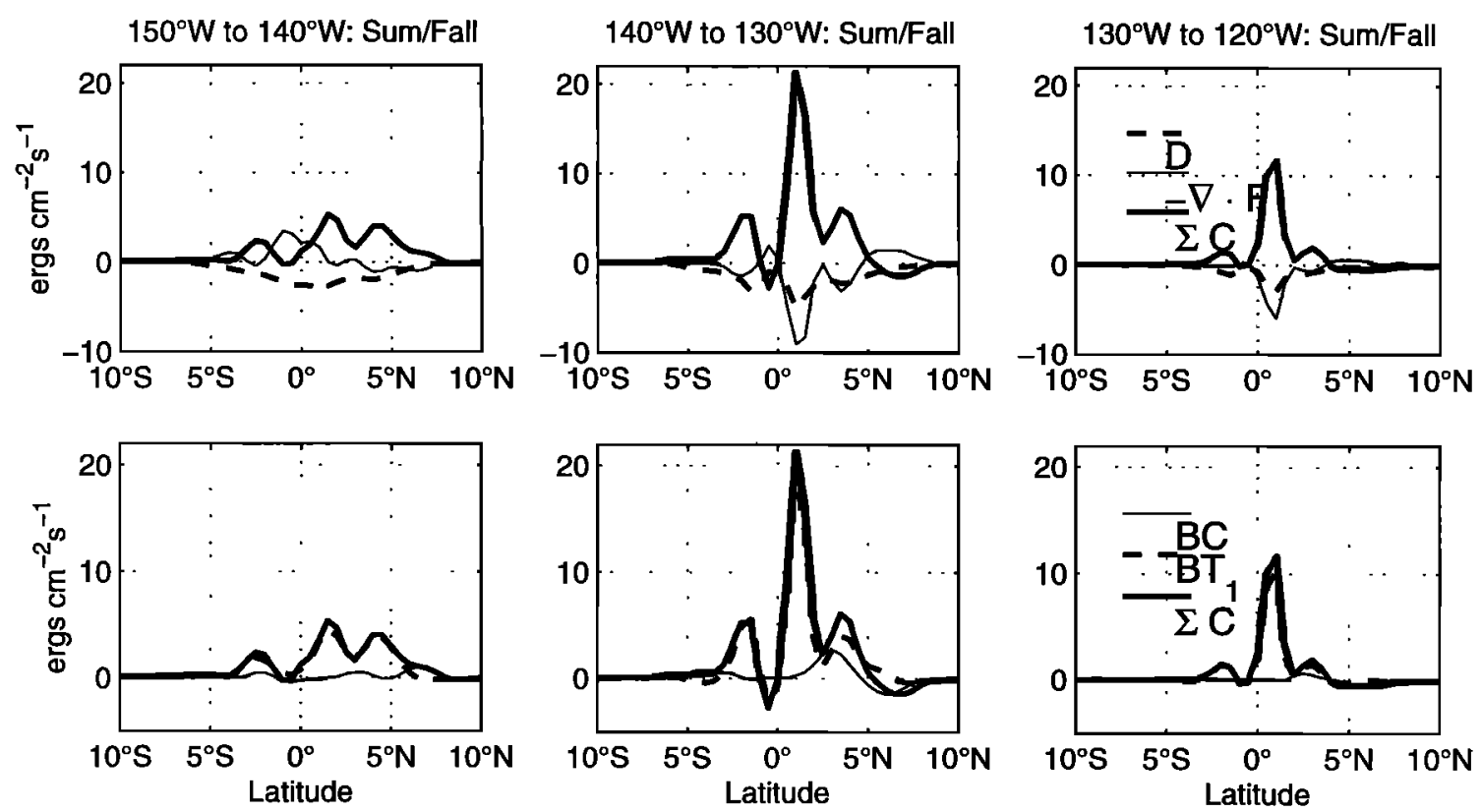

Figure 7. Top panels show the three largest terms in the eddy-energy budget: flux-divergence (thin line), mean-flow to eddy conversion (thick line), and dissipation (thick dashed line) for three regional averages during summer through fall (June through December) in erg $\mathrm{cm}^{-2} \mathrm{~s}^{-1}$. Bottom panels show the conversion terms (thick line) and its constituents, upper-layer barotropic conversion (thick dashed line) and baroclinic conversion (thin line). 
$150^{\circ} \mathrm{W}$ to $140^{\circ} \mathrm{W}$ : Winter
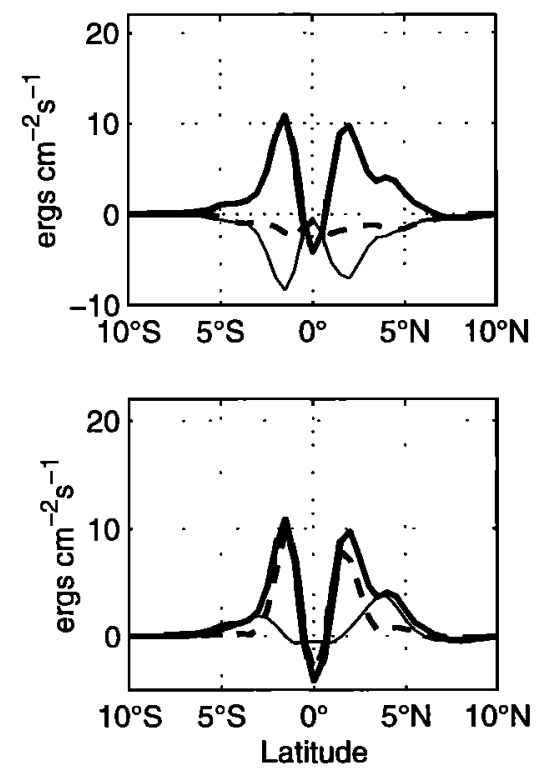

$140^{\circ} \mathrm{W}$ to $130^{\circ} \mathrm{W}$ : Winter
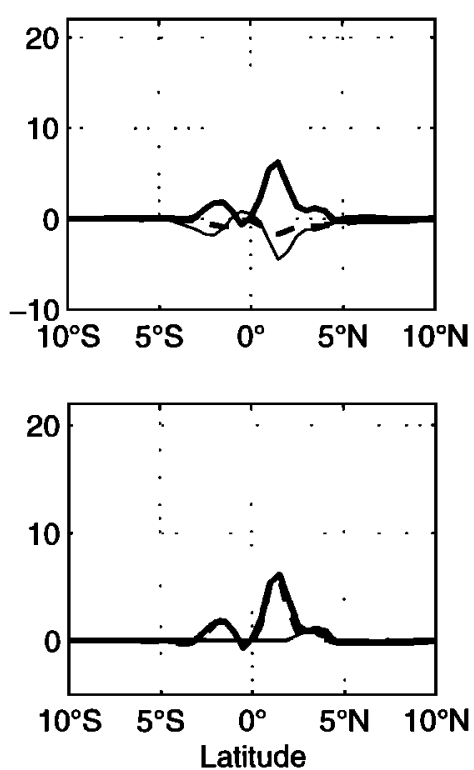

$130^{\circ} \mathrm{W}$ to $120^{\circ} \mathrm{W}$ : Winter
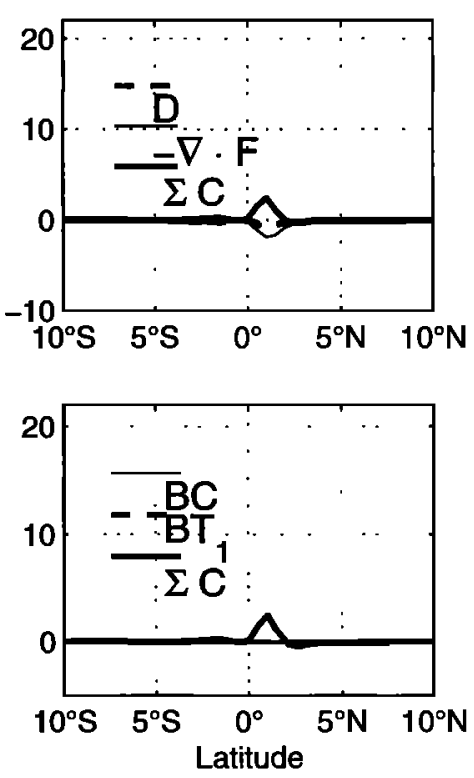

Figure 8. Same as Figure 7 but for the winter (December through March).

The three largest terms in the eddy-energy budget are the flux-divergence term, the conversion term, and the dissipation term. These terms, calculated during boreal summer/fall (June through December) and boreal winter (January through March) and regionally averaged $\left(150^{\circ} \mathrm{W}\right.$ to $140^{\circ} \mathrm{W}, 140^{\circ} \mathrm{W}$ to $130^{\circ} \mathrm{W}$, and $130^{\circ} \mathrm{W}$ to $120^{\circ} \mathrm{W}$ ), are shown in Figures 7 and 8. While temporal and longitudinal dependence exists in the eddy-energy budget, some general similarities appear. The conversion terms are asymmetric: strongest in the northern hemisphere. Except in the region $130^{\circ} \mathrm{W}$ to $120^{\circ} \mathrm{W}$ during the winter period, conversion terms appear to have a double-core structure, one core near $1^{\circ}-2^{\circ} \mathrm{N}$ and a second near $3^{\circ}-4^{\circ} \mathrm{N}$. The dominant conversion terms are baroclinic (11) and upper-layer barotropic (10) . Barotropic conversion in the lower layer and KelvinHelmoholtz conversion in both layers are very small throughout the region $\left(150^{\circ} \mathrm{W}-120^{\circ} \mathrm{W}\right)$. Generally, maximum baroclinic conversion occurs near the cores of the SEC; maximum upper-layer barotopic conversion coincides with the edges of the SEC (Figure 9). The flux-divergence terms also generally mirror the bimodal structure of the conversion terms north of the equator (Figures 7 and 8).

The westward progression of upper-layer current intensification is evident in the energy budget. During boreal summer and fall, energy conversions are largest east of $140^{\circ} \mathrm{W}$. During boreal winter, conversion terms are largest west of $140^{\circ} \mathrm{W}$. The second northern peak (near $4^{\circ} \mathrm{N}$ ) in the conversion term disappears east of $130^{\circ} \mathrm{W}$ during the winter (Figure 8, right panels). During this time, the off-equatorial wave is weak $<20 \mathrm{~cm} \mathrm{~s}^{-1}$ east of $130^{\circ} \mathrm{W}$ (Figure 6).

The ratios of the average contributions of baroclinic to upper-layer barotropic conversions are given in Ta- ble 2. In the central region, $140^{\circ} \mathrm{W}$ to $130^{\circ} \mathrm{W}$, the partitioning between baroclinic and upper-layer barotropic changes little during June through March. In the eastern region, $130^{\circ} \mathrm{W}$ to $120^{\circ} \mathrm{W}$, the early stages of instability are dominated by upper-layer barotropic conversions. Between $150^{\circ} \mathrm{W}$ and $140^{\circ} \mathrm{W}$, the baroclinic conversion becomes increasingly important during the wave season. There is little conversion from mean-potential to eddy energy during the summer/fall, but during winter the off-equatorial peak in upper-layer barotropic conversion is replaced by a baroclinic conversion of comparable magnitude (Figure 8 , bottom left panel). From the summer/fall period to the winter period, the NECC at $150^{\circ} \mathrm{W}-140^{\circ} \mathrm{W}$ weakens while the SEC strengthens with little net effect on the horizontal shear between the two currents (Figure 9). However, since the SEC has intensified and moved slightly further north, the gradients in layer thickness have increased, and perhaps this favors the baroclinic conversion (Figure 9).

\section{Discussion and Conclusions}

Two upper-layer wave processes are identified in the model simulation of tropical circulation. A westward propagating 15-day wave with approximately $1100 \cdot \mathrm{km}$ wavelength has strong meridional velocity signal centered on the equator. The sea-level and zonal velocity signals associated with this equatorial wave have maxima near $1.5^{\circ} \mathrm{N}$ and $1.5^{\circ} \mathrm{S}$. A 30-day off-equatorial wave is also westward propagating with wavelength near $1100 \mathrm{~km}$. However, it is asymmetric with respect to the equator, having maximum sea-level and meridional velocity amplitudes near $6^{\circ} \mathrm{N}$ and $4^{\circ} \mathrm{N}$, respectively. Both wave-like processes exhibit the same seasonal modula- 

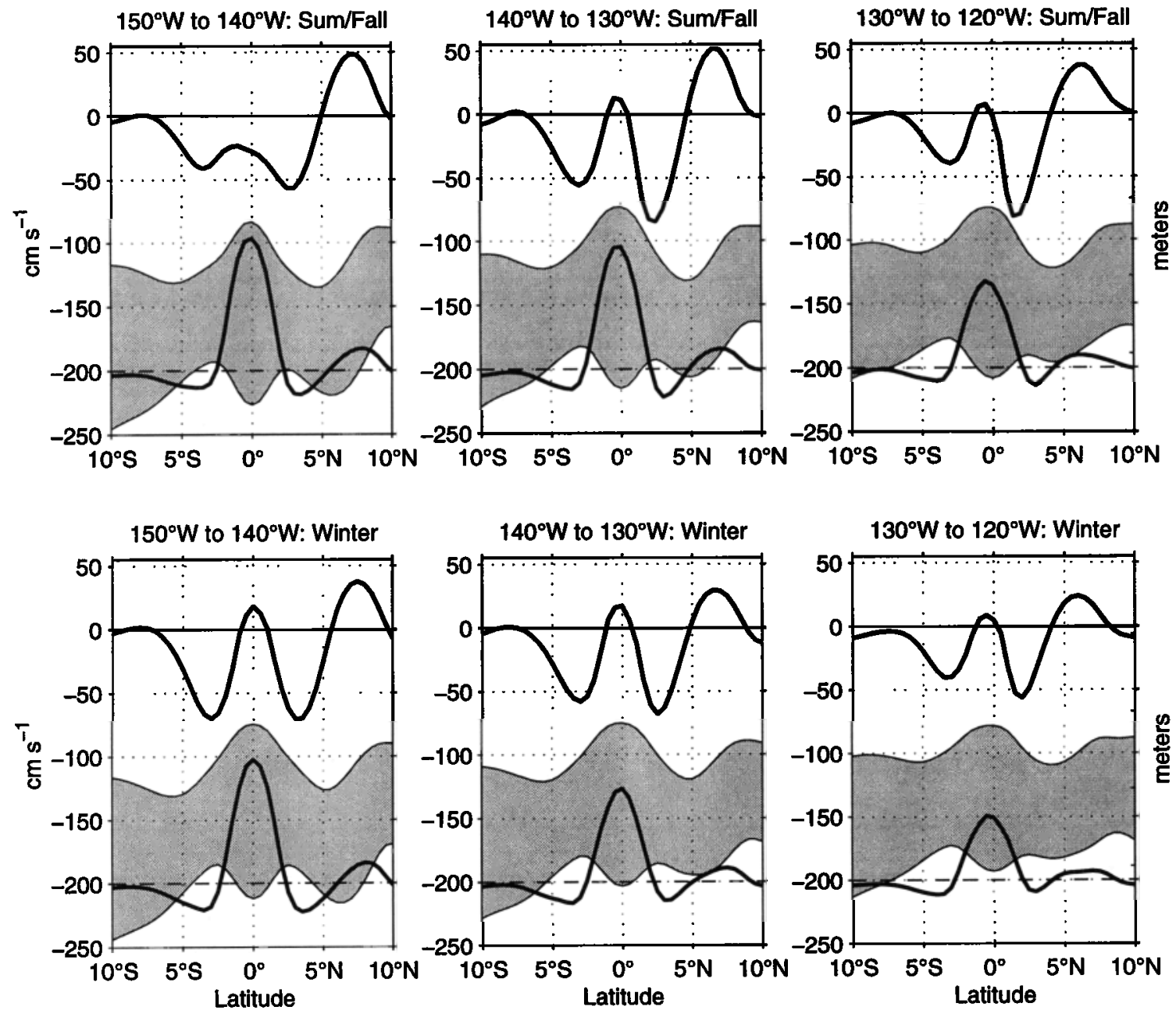

Figure 9. Mean zonal velocity in the upper layer and lower layer (offset by $-200 \mathrm{~cm} \mathrm{~s}^{-1}$ ) in thick black lines. The mean-vertical structure is superimposed on each panel: upper layer is unshaded, lower layer is shaded. Panels are for three regional and two seasonal averages as labeled.

tion: strong in boreal fall/winter, weak in boreal spring.

There is observational evidence for both of these wave-like processes in the tropical Pacific. Hansen and Paul [1984] reported that surface buoys which crossed $1.5^{\circ} \mathrm{N}$ experienced a change in direction of rotation: counterclockwise to the south and clockwise to the north of $1.5^{\circ} \mathrm{N}$. These counterclockwise eddies, sam-

Table 2. Ratio of Contribution of Total Baroclinic Conversion to Total Upper-Layer Barotropic Conversion for Boreal Summer/Fall (June Through December) and Boreal Winter (January Through March)

\begin{tabular}{lcc}
\hline & Summer/Fall & Winter \\
\hline $150^{\circ} \mathrm{W}$ to $140^{\circ} \mathrm{W}$ & 0.19 & 0.48 \\
$140^{\circ} \mathrm{W}$ to $130^{\circ} \mathrm{W}$ & 0.22 & 0.18 \\
$130^{\circ} \mathrm{W}$ to $120^{\circ} \mathrm{W}$ & 0.11 & 0.18
\end{tabular}

Totals represent sums of positive contributions only, for the longitude ranges specified and latitudes between $10^{\circ} \mathrm{N}$ and $10^{\circ} \mathrm{S}$. pled during the TIWE experiment, are confined to narrow period and wavelength ranges around at 21 days and $1060 \mathrm{~km}$, respectively, that is, westward phase speed of $51 \mathrm{~cm} \mathrm{~s}^{-1}$ [Qiao and Weisberg, 1995]. Further north, at $5^{\circ}-9^{\circ} \mathrm{N}$, Périgaud [1990], McPhaden [1996], and Flament et al. [1996] observed clockwise oscillations propagating westward with speeds in the range of $30-40 \mathrm{~cm} \mathrm{~s}^{-1}$.

The model eddy-energy budget reveals strong conversions from mean-flow to eddy field through upper-layer barotropic and baroclinic conversion terms. Conversion terms north of the equator exhibit a bimodal structure. One maximum between the equator and $3^{\circ} \mathrm{N}$ has conversions dominated by upper-layer barotropic conversion spatially coincident with the cyclonic shear along the equatorward edge of the SEC. The other is a second, smaller maximum between $3^{\circ} \mathrm{N}$ and $5^{\circ} \mathrm{N}$, where conversion terms are a combination of upper-layer barotropic conversion along the poleward edge of the SEC (anticyclonic shear) and baroclinic conversion embedded in the SEC. The energetics budget determined by Hansen and Paul [1984] shows the same structure: bar- 
otropic conversion along the cyclonic and anticyclonic SEC shear regions and baroclinic conversion within the SEC. This double-peak conversion term, combined with similar structure in the flux-divergence terms in the model eddy-energy budget, provides evidence that two distinct instabilities are generated at the different source regions, one near the equator and a second between $2^{\circ} \mathrm{N}$ and $5^{\circ} \mathrm{N}$.

A temporal and longitudinal dependence exists in the eddy-energy budget. The westward progression of upper-layer current intensification is evident in the energy budget. During boreal summer and fall, energy conversions are largest east of $140^{\circ} \mathrm{W}$, while during winter, conversion terms are largest west of $140^{\circ} \mathrm{W}$. In the western and eastern instability regions, $150^{\circ} \mathrm{W}$ to $140^{\circ} \mathrm{W}$ and $130^{\circ} \mathrm{W}$ to $120^{\circ} \mathrm{W}$, respectively, the partitioning of conversion between baroclinic and barotropic changes during the year. At $150^{\circ} \mathrm{W}-140^{\circ} \mathrm{W}$, there is a transition from barotropic conversion along the SEC shear zones during summer and fall to baroclinic conversion within the SEC during winter, similar to the results of Luther and Johnson [1990]. To the east, at $130^{\circ}-120^{\circ} \mathrm{W}$, the early stages of instability are almost entirely dominated by barotropic conversion.

Proehl [1996] recently readdressed the utility of using energy conversion terms in the classification of flow instabilities, stressing the importance of the geometry of the flow. He showed that the partitioning of baroclinic and barotropic conversion in the linear instability analysis of a westward jet changed as the core moved from $2^{\circ}$ to $6^{\circ}$ latitude, although the unstable wave structure changed little. As the geostrophically balanced jet moves further north, baroclinic conversion dominates, reflecting the increase in isopycnal slopes.

Using the insight of Proehl [1996], we can interpret the model simulation in the following way. The SEC becomes unstable during boreal summer through boreal winter. The instability is manifested in two wave processes. Because the background flow field is constantly changing as a function of time and longitude, the available energy that the instabilites can extract is also changing.

We do not expect the results from this modeling effort to duplicate the real ocean in detail, because the model physics are highly simplified. For example, the role of the surface density front near $1.5^{\circ} \mathrm{N}$ cannot be addressed with our model configuration, and McCreary and $Y u$ [1992] and $Y u$ et al. [1995] have suggested that instability of this front provides an additional source of eddy energy. However, the similarities of the meridional structures of the observed and modeled tropical instability waves and the conversion terms suggest that our model has captured much of the essential physics. The results emphasize the importance of the meridional structure of the tropical instability waves and the temporal and longitudinal variations in eddy-energy conversion terms, which depend on the local current and density fields. Future modeling efforts incorporating more realistic tropical physics should address the im- pact of both near-equatorial and off-equatorial variability on the regional heat and momentum budgets.

\section{Appendix: Energy Equations}

The total, mean-flow, and eddy energy equations are the same as in the work by McCreary and Yu [1992], except in this case layer densities remain constant.

\section{A.1. Total Energy Equations}

Consider the momentum and continuity equations for each layer of a two-and-a-half-layer ocean. The subscript on the variables indicates the layer. Unless directly stated, $i=1,2$.

$$
\begin{aligned}
\frac{\partial \mathbf{v}_{i}}{\partial t} & +\mathbf{v}_{i} \cdot \nabla \mathbf{v}_{i}+\hat{k} \times f \mathbf{v}_{i}= \\
& -\frac{\nabla p_{i}}{\rho_{o}}+\frac{\boldsymbol{\tau}}{\rho_{1} h_{1}}+A_{H} \nabla^{2} \mathbf{v}_{i}+\mathbf{W}_{\mathbf{m} i} \\
\frac{\partial h_{i}}{\partial t} & +\nabla \cdot h_{i} \mathbf{v}_{i}=\mathbf{W}_{\mathbf{c} i} \\
\nabla p_{1} & =g\left(\rho_{1}-\rho_{3}\right) \nabla h_{1} \\
& +g\left(\rho_{2}-\rho_{3}\right) \nabla h_{2} \\
\nabla p_{2} & =g\left(\rho_{2}-\rho_{3}\right) \nabla\left(h_{1}+h_{2}\right) \\
\nabla p_{3} & =0
\end{aligned}
$$

For convenience, the entrainment terms are written as

$$
\begin{aligned}
\mathbf{W}_{\mathbf{m} i} & =\max \left[0,-\omega_{i-1}\right] \frac{\mathbf{v}_{\imath-1}}{h_{i}} \\
& +\max \left[0, \omega_{i}\right] \frac{\mathbf{v}_{i+1}}{h_{i}} \\
& -\left(\max \left[0,-\omega_{i}\right]\right. \\
& \left.+\max \left[0, \omega_{i-1}\right]\right) \frac{\mathbf{v}_{i}}{h_{i}} \\
\mathbf{W}_{\mathbf{c} i} & =\omega_{i}-\omega_{i-1} .
\end{aligned}
$$

Note throughout that a repeated index does not imply summing in (A1) through (A2) and (A6) through (A7).

Define the kinetic energy, $K_{i}$, for each layer,

$$
K_{i} \equiv \frac{1}{2} \rho_{i} h_{i} \mathbf{v}_{i} \cdot \mathbf{v}_{i} .
$$

As in the work by McCreary and Yu [1992], potential energy is

$$
P E \equiv \int_{z^{\prime}}^{d} \rho g z d z
$$

where $d$ is the elevation above the undisturbed free surface and $z^{\prime}$ is an arbitrary reference depth in layer 3. For the two-and-a-half-layer ocean

$$
\begin{aligned}
P E & =\frac{1}{2}\left[\left(\rho_{1}-\rho_{2}\right) g h_{1}^{2}\right. \\
& \left.+\left(\rho_{2}-\rho_{3}\right) g\left(h_{1}+h_{2}\right)^{2}\right] .
\end{aligned}
$$

An equation expressing the rate of change of kinetic energy is obtained by taking the dot product of $\rho_{i} h_{i} \mathbf{v}_{i}$ with (A1) and the product of $\frac{1}{2} \rho_{i} \mathbf{v}_{i} \cdot \mathbf{v}_{i}$ with (A2) and summing. The rate of change of potential energy is de- 
termined by substituting expressions from (A2) through (A5) and (A9) into $\partial P E / \partial t$.

$$
\frac{\partial \mathcal{E}}{\partial t}+\nabla \cdot \mathcal{F} \mathcal{L U X}=\mathcal{T}+\mathcal{D}+\mathcal{W}
$$

Total energy of the flow is given by

$$
\mathcal{E}=K E_{i}+P E .
$$

Flux-divergence terms are given by

$$
\nabla \cdot \mathcal{F} \mathcal{L U X}=\nabla \cdot \mathbf{v}_{i}\left(K E_{i}+P E\right) .
$$

Mechanical energy input is given by

$$
\mathcal{T}=h_{i} \mathbf{v}_{i} \cdot \frac{\tau}{h_{i}} .
$$

Viscous dissipation is given by

$$
\mathcal{D}=\rho_{i} A_{H} h_{i} \mathbf{v}_{i} \cdot \nabla^{2} \mathbf{v}_{i} .
$$

Entrainment and detrainment are given by

$$
\begin{aligned}
\mathcal{W} & =\rho_{i} h_{i} \mathbf{v}_{i} \cdot \mathbf{W}_{\mathbf{m} i}+\frac{1}{2} \rho_{i} \mathbf{v}_{i} \mathbf{v}_{i} \cdot \mathbf{W}_{\mathbf{c} i} \\
& +p_{i} \cdot \mathbf{W}_{\mathbf{c} i} .
\end{aligned}
$$

\section{A.2. Mean Energy Equations}

Decompose each variable $s$ into mean and eddy components:

$$
s=\bar{s}+s^{\prime} \quad \text { where } \bar{s}=\frac{1}{T} \int_{t_{\mathrm{o}}}^{t_{\mathrm{o}}+T} s d t .
$$

Assume that $T$ is some time period much longer than the timescale of the variability. Decomposing for $u, v, h$, and $p$ in this way and taking the average (A1) through (A5). yields equations for mean momentum and mean continuity:

$$
\begin{aligned}
\frac{\partial \overline{\mathbf{v}_{i}}}{\partial t}+ & \overline{\mathbf{v}_{i}} \cdot \nabla \overline{\mathbf{v}_{i}}+\overline{\mathbf{v}_{i}^{\prime} \cdot \nabla \mathbf{v}_{i}^{\prime}}+\hat{k} \times f \overline{\bar{v}_{i}}=-\nabla \overline{p_{i}} \\
& +\overline{\left(\frac{\tau}{\rho_{i} h_{i}}\right)}+A_{H} \nabla^{2} \overline{\mathbf{v}_{i}}+\overline{\mathbf{W}_{\mathbf{m} i}}, \\
\frac{\partial \overline{h_{i}}}{\partial t}+ & =\nabla \cdot \overline{h_{i}} \overline{\mathbf{v}_{i}}+\nabla \cdot \overline{h_{i}^{\prime} \mathbf{v}_{i}^{\prime}}=\overline{\mathbf{W}_{\mathbf{c} i}}, \\
\nabla \overline{p_{1}} & =g\left(\rho_{1}-\rho_{3}\right) \nabla \overline{h_{1}} \\
& +g\left(\rho_{2}-\rho_{3}\right) \nabla \overline{h_{2}}, \\
\nabla \overline{p_{2}}= & g\left(\rho_{2}-\rho_{3}\right) \nabla\left(\overline{h_{1}}+\overline{h_{2}}\right), \\
\nabla \overline{p_{3}}= & 0 . \\
\overline{\mathbf{W}_{\mathbf{m}}} & =\frac{\max \left[0,-\omega_{i-1}\right] \frac{\mathbf{v}_{i-1}}{h_{i}}}{\left(\max \left[0,-\omega_{i-1}\right]+\max \left[0, \omega_{i-1}\right]\right) \frac{\mathbf{v}_{i}}{h_{i}}} \\
& +\overline{\max \left[0, \omega_{i}\right] \frac{\mathbf{v}_{i+1}}{h_{i}}}
\end{aligned}
$$

$$
\overline{\mathbf{W}_{c i}}=\overline{\omega_{i}}-\overline{\omega_{i-1}} .
$$

Note that a repeated index does not imply summing in (A11) through (A12) and (A16) through (A17).

The mean-flow kinetic energy in each layer is

$$
\tilde{K}_{i}=\frac{1}{2} \rho \overline{h_{i}} \overline{\mathbf{v}_{i}} \cdot \overline{\mathbf{v}_{i}} .
$$

The mean-flow potential energy is defined as

$$
\begin{aligned}
\widetilde{P E} & =\frac{1}{2}\left(\rho_{1}-\rho_{2}\right) g{\overline{h_{1}}}^{2} \\
& +\frac{1}{2}\left(\rho_{2}-\rho_{3}\right) g\left(\overline{h_{1}}+\overline{h_{2}}\right)^{2} .
\end{aligned}
$$

The equation for the kinetic energy of the mean flow is found by multiplying the mean-momentum equation, (A11), by $\rho_{i} \overline{h_{i}} \overline{\mathbf{v}_{i}}$ and the mean-continuity equation, (A12), by $\frac{1}{2} \rho_{i}{\overline{v_{i}}}^{2}$ for each layer and summing the results. The rate of change of mean-flow potential energy is found by using expressions in (A12) through (A15) and (A18).

$$
\frac{\partial \widetilde{\mathcal{E}}}{\partial t}+\nabla \cdot \widetilde{\mathcal{F} \mathcal{L} \mathcal{X}}=\tilde{\mathcal{T}}+\widetilde{\mathcal{D}}+\widetilde{\mathcal{W}}-C
$$

Total energy of the mean flow is given by

$$
\widetilde{\mathcal{E}}=\widetilde{K}_{i}+\widetilde{P E} \text {. }
$$

Flux divergence terms are given by

$$
\begin{aligned}
\nabla \cdot \widetilde{\mathcal{F} \mathcal{L} \mathcal{X}} & =\nabla \cdot\left[\overline{\mathbf{v}_{i}}\left(\overline{K_{i}}+\overline{h_{i}} \overline{\overline{p_{i}}}\right)\right] \\
& +\nabla \cdot\left[\overline{h_{i}^{\prime} \mathbf{v}_{i}^{\prime}}\left(\frac{1}{2} \rho_{i}\left(\overline{u_{i}}{ }^{2}+{\overline{v_{i}}}^{2}\right)+\overline{p_{i}}\right)\right] \\
& +\nabla \cdot\left[\rho_{i} \overline{h_{i}} \overline{u_{i}} \overline{\bar{v}_{i}^{\prime} u_{i}^{\prime}}+\rho_{i} \overline{h_{i}} \overline{v_{i}} \overline{\mathbf{v}_{i}^{\prime} \bar{v}_{i}^{\prime}}\right]
\end{aligned}
$$

Mechanical energy input is given by

$$
\tilde{\mathcal{T}}=\overline{h_{1}} \overline{\mathbf{v}_{1}} \cdot \overline{\left(\frac{\tau}{h_{1}}\right)} .
$$

Viscous dissipation is given by

$$
\tilde{\mathcal{D}}=\rho_{i} A_{H} \overline{h_{i}} \overline{\mathbf{v}_{i}} \cdot \nabla^{2} \overline{\mathbf{v}_{i}} .
$$

Entrainment and detrainment are given by

$$
\begin{aligned}
\widetilde{\mathcal{W}} & =\rho_{i} \overline{h_{i}} \overline{\mathbf{v}_{i}} \cdot \overline{\mathbf{W}_{\mathbf{m} i}} \\
& +\frac{1}{2} \rho_{i} \overline{\mathbf{v}}_{i}{ }^{2} \overline{\mathbf{W}_{\mathbf{c} i}}+\overline{p_{i}} \overline{\mathbf{W}_{\mathbf{c}_{i}}} .
\end{aligned}
$$

Conversion terms are as follows

$$
\begin{aligned}
& C= \\
& -\rho_{i} \overline{h_{i}^{\prime} \mathbf{v}_{i}^{\prime} \overline{u_{i}}} \cdot \nabla \overline{u_{i}}-\rho_{i} \overline{h_{i}^{\prime} \mathbf{v}_{i}^{\prime} \overline{v_{\imath}}} \cdot \nabla \overline{v_{i}} \\
& -\quad \rho_{i} \overline{h_{i}} \overline{\mathbf{v}_{i}^{\prime} u_{i}^{\prime}} \cdot \nabla \overline{u_{i}}-\rho_{i} \overline{h_{i}} \overline{\mathbf{v}_{i}^{\prime} v_{i}^{\prime}} \cdot \nabla \overline{v_{i}} \\
& \text { - } \rho_{i} \overline{u_{i}} \overline{u_{i}^{\prime} \nabla \cdot \overline{h_{i}} \mathbf{v}_{i}^{\prime}}-\rho_{i} \overline{v_{i}} \overline{v_{i}^{\prime} \nabla \cdot \overline{h_{i}} \mathbf{v}_{i}^{\prime}} \\
& \text { - } \overline{h_{i}^{\prime} \mathbf{v}_{i}^{\prime}} \cdot \nabla \overline{p_{i}} \text {. }
\end{aligned}
$$




\section{A.3. Eddy Energy Equation}

An equation describing the rate of change of the energy associated with the eddy field is obtained by subtracting (A19) from the mean of the total energy equation (A10):

$$
\begin{aligned}
\frac{\partial \widehat{\mathcal{E}}}{\partial t}+\nabla \cdot \widehat{\mathcal{F} \mathcal{L} \mathcal{X}} & =\widehat{\mathcal{T}}+\widehat{\mathcal{D}}+\widehat{\mathcal{W}}+C, \\
\widehat{\mathcal{E}} & =\overline{\mathcal{E}}-\widetilde{\mathcal{E}} \\
\nabla \cdot \widehat{\mathcal{F} \mathcal{L} \mathcal{X}} & =\overline{\nabla \cdot \mathcal{F} \mathcal{L} \mathcal{X}}-\nabla \cdot \widetilde{F} \widetilde{\mathcal{L}} \mathcal{X} \\
\widehat{\mathcal{T}} & =\overline{\mathcal{T}}-\widetilde{\mathcal{T}} \\
\widehat{\mathcal{D}} & =\overline{\mathcal{D}}-\widetilde{\mathcal{D}} \\
\widehat{\mathcal{W}} & =\overline{\mathcal{W}}-\widetilde{\mathcal{W}} .
\end{aligned}
$$

Acknowledgments. Harley Hurlburt graciously provided access to the Navy layered ocean model and gave many helpful suggestions. Special thanks to E. Joseph Metzger and Allan Wallcraft for assistance during the model setup and subsequent runs. Comments from two anonymous reviewers have greatly improved the paper.

\section{References}

Cox, M. D., Generation and propagation of 30-day waves in a numerical model of the Pacific, J. Phys. Oceanogr., 10, 1168-1186, 1980.

Donohue, K. A., Wave propagation in the central equatorial Pacific Ocean, Ph. D. thesis, Univ. of R.I., Narragansett, 1995.

Donohue, K. A., M. Wimbush, X. Zhu, S. M. Chiswell, R. Lukas, L. Miller, and H. E. Hurlburt, Five years' central Pacific sea level from in situ array, satellite altimeter and numerical model, Atmos.-Ocean, 32, 495-506, 1994.

Flament, P. J., S. C. Kennan, R. A. Knox, P. P. Niiler, and R. L. Bernstein, The three-dimensional structure of an upper ocean vortex in the tropical Pacific Ocean, $\mathrm{Na}$ ture, 382, 610-613, 1996.

Giese, B. S., J. A. Carton, and L. J. Holl, Sea-level variability in the eastern tropical Pacific as observed by TOPEX and Tropical Ocean-Global Atmosphere Tropical Atmosphere-Ocean Experiment, J. Geophys. Res., 99, 24739-24748, 1994.

Hansen, D. V., and C. A. Paul, Genesis and effects of long waves in the equatorial Pacific, J. Geophys. Res., 89, 10431-10440, 1984.

Hellerman, S., and M. Rosenstein, Normal monthly windstress over the world ocean with error estimates, J. Phys. Oceanogr., 13, 1093-1104, 1983.

Hurlburt, H. E., A. J. Wallcraft, Z. Sirkes, and E. J. Metzger, Modeling of the global and Pacific oceans: On the path to eddy-resolving ocean prediction, Oceanography, 5 , 9-18, 1992.

Levitus, S., Climatological Atlas of the World Ocean, NOAA Prof. Pap. 13, Natl. Oceanic and Atmos. Admin., Rockville, Md., 1982.

Luther, D. S., and E. S. Johnson, Eddy energetics in the upper equatorial Pacific during the Hawaii-to-Tahiti Shuttle Experiment, J. Phys. Oceanogr., 20, 913-944, 1990.

McCreary, J. P., and Z. Yu, Equatorial dynamics in a twoand-a-half layer model, Prog. Oceanogr., 29, 61-132, 1992.

McPhaden, M. J., Monthly period oscillations in the Pacific North Equatorial Countercurrent, J. Geophys. Res., 101, 6337-6359, 1996.

Périgaud, C., Sea level oscillations observed with Geosat along the two shear fronts of the Pacific North Equatorial Countercurrent, J. Geophys. Res., 95, 7239-7248, 1990.

Philander, S. G. H., D. Halpern, D. Hansen, R. Legeckis, L. Miller, C. Paul, D. R. Watts, R. Weisberg, and M. Wimbush, Long waves in the equatorial Pacific Ocean, Eos Trans. AGU, 66, 154-155, 1985.

Polito, P., and P. Cornillon, Long baroclinic Rossby waves detected by the TOPEX/POSEIDON, J. Geophys. Res., 102, 3215-3235, 1997.

Proehl, J. A., Linear stability of equatorial zonal flows, $J$. Phys. Oceanogr., 26, 601-621, 1996.

Qiao, L., and R. H. Weisberg, Tropical instability wave kinematics: Observations from the Tropical Instability Wave Experiment, J. Geophys. Res., 100, 8677-8693, 1995.

Qiao, L., and R. H. Weisberg, Tropical Instability Wave energetics: Observations from the Tropical Instability Wave Experiment, J. Phys. Oceanogr., 28, 345-360, 1998.

Semtner, A. J., and W. R. Holland, Numerical simulation of equatorial ocean circulation. I, A basic case in turbulent equilibrium, J. Phys. Oceanogr., 10, 667-693, 1980.

Shriver, J. F., and H. E. Hurlburt, The contribution of the global thermohaline circulation to the Pacific to Indian Ocean throughflow via Indonesia, J. Geophys. Res., 102, 5491-5512, 1997.

Wallcraft, A. J., Navy layered ocean model users guide, NOARL Rep. 35, Naval Oceangr. and Atmos. Res. Lab., Stennis Space Center, Miss., 1991.

Yu, Z., J. P. McCreary, and J. A. Proehl, Meridional asymmetry and energetics of tropical instability waves, $J$. Phys. Oceanogr., 25, 2997-3007, 1995.

K. A. Donohue, School of Ocean and Earth Science and Technology, University of Hawaii, Honolulu, HI 96882. (email: kathyd@soest.hawaii.edu)

M. Wimbush, Graduate School of Oceanography, University of Rhode Island, South Ferry Road, Narragansett, RI 02882. (e-mail: markw@ono.gso.uri.edu)

(Received October 31, 1996; revised December 23, 1997; accepted February 26, 1998.) 